\title{
Emerging regulators of vascular smooth muscle cell migration
}

\author{
TecLino Afewerki ${ }^{1} \cdot$ Sultan Ahmed ${ }^{1} \cdot$ Derek Warren $^{1}$
}

Received: 29 April 2019 / Accepted: 21 June 2019 / Published online: 28 June 2019

(c) The Author(s) 2019

\begin{abstract}
Vascular smooth muscle cells (VSMCs) are the predominant cell type in the blood vessel wall and normally adopt a quiescent, contractile phenotype. VSMC migration is tightly controlled, however, disease associated changes in the soluble and insoluble environment promote VSMC migration. Classically, studies investigating VSMC migration have described the influence of soluble factors. Emerging data has highlighted the importance of insoluble factors, including extracellular matrix stiffness and porosity. In this review, we will recap on the important signalling pathways that regulate VSMC migration and reflect on the potential importance of emerging regulators of VSMC function.
\end{abstract}

Keywords Vascular smooth muscle cell $\cdot$ Migration $\cdot$ Signalling $\cdot$ Mechanotransduction

\section{Introduction}

Cell migration begins at the earliest stages of life and it continuous as a fundamental process for survival (VicenteManzanares et al. 2005). Smooth muscle cells are found in the hollow organs of the vascular, reproductive, urinary and digestive systems. In the vascular system, the vascular smooth muscle cells (VSMCs) are located in the tunica media between the loose connective tissue of the tunica adventitia and the endothelial layer of the tunica intima (Ahmed and Warren 2018). VSMC migration occurs during several important physiological and pathological processes ranging from early remodelling, response to injury, vascular disease (Tahir et al. 2015; Cai et al. 2015). VSMC migration is activated in response to multiple environmental cues including chemotactic, haptotatic and durotactic signals (Isenberg et al. 2009; Hartman et al. 2016; Kerr et al. 2013). Promigratory stimuli activate signal transduction cascades that trigger remodelling of the actin cytoskeleton and cell-extracellular matrix (ECM) adhesions that increase the migration capacity of VSMCs (Gerthoffer 2007). Similarly to other cell types, VSMC directional migration is initiated

TecLino Afewerki and Sultan Ahmed contributed equally to this work.

Derek Warren

derek.warren@uea.ac.uk

1 School of Pharmacy, University of East Anglia, Norwich Research Park, Norwich NR4 7TJ, UK by external signals that stimulate receptors on the cell surface, activating multiple signalling cascades that alter the cytoskeletal structure of the cell (Gerthoffer 2007). Typically, stimulation is initiated via $\mathrm{G}$ protein coupled receptors (GPCRs) and receptor tyrosine kinases (RTKs), which in turn activate several downstream signalling pathways (Scherberich et al. 2000). Migration is a cyclical process, with external signalling inducing polarisation and filopodial projections, followed by lamellipodia extending from the cell (Louis and Zahradka 2010). This forms the leading edge of the cell. Nascent adhesions form, serving as anchor points for the newly formed protrusion to its ECM (Fig. 1). These adhesions associate with filamentous actin and actomyosin activity pulls the cell body forward (Fig. 1). Adhesions also serve as signalling conduits, allowing "inside-out" signalling by emitting the traction force generated by the cell (Ross et al. 2013). The force generated causes "outside-in" signalling to occur which further regulates the dynamics and maturation of the focal adhesions (Wrighton 2013). At the same time, adhesion disassembly and actomyosin activity detach and retract the rear of the cell, further propelling the cell body forward (Fig. 1).

Directional cell migration is often influenced by the two-dimensional and three-dimensional organization of the ECM. Recently, there have been advances in our understanding of cell migration. Specifically, around the establishment of polarity, the dynamic regulation of actin and microtubule polymerization, and the management of spatial and temporal signal transduction. We aim to address the key steps, 
Fig. 1 Stages of VSMC migration. Blue lines represent actin filaments. Black lines represent cell-matrix adhesions. Grey line represents extracellular matrix
(A) Resting cell

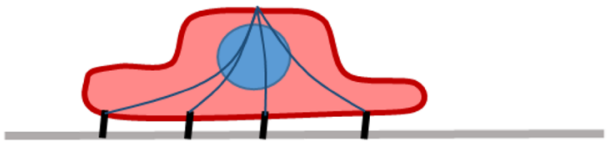

Cdc42

$\checkmark$

mDia

$\checkmark$

Filopodial formation

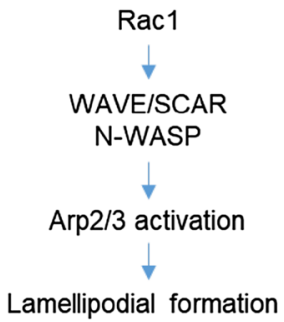

- Maturation of nascent adhesions

- Actomyosin contraction pulls the cell body forward leading edge

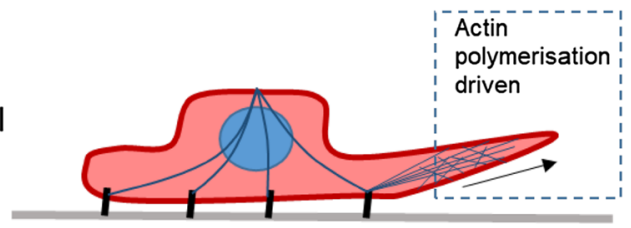

Lamellipodial formation
(D) Rear end detachment

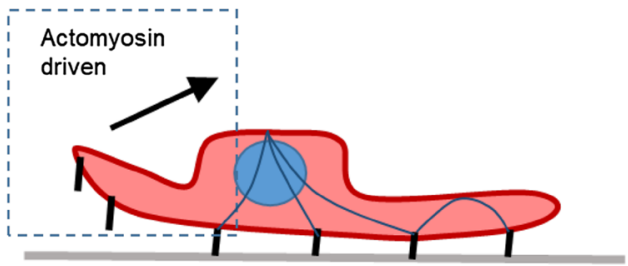

(E) Cell migration
- Calpains and MMPs promote cell-ECM adhesion disassembly

- Actomyosin contraction exceeds adhesion strength

- Rear end detachment

- Cell is propelled forward

- Focal adhesion proteins are recycled from cell rear important signalling pathways and critical regulators of aortic VSMC migration.

\section{Aortic mechanically properties and compliance}

The medial layer of the aortic wall contains elastic and nonelastic extracellular matrix components (Wagenseil and Mecham 2009). Elastin provides the majority of the elasticity, whereas non-elastic collagen-I provides tensile strength to the medial layer (Wagenseil and Mecham 2009). This elasticity is essential for the aorta to respond to changes in blood pressure; as blood pulse moves along the vessel, the aortic wall expands and recoils behind the blood pulse returning the aorta to its original shape (Raij and GonzalezOchoa 2011). This phenomenon is known as aortic compliance and this is essential for cardiovascular health (Raij and Gonzalez-Ochoa 2011). The rigidity of the aortic wall determines how compliant the vessel is; if the wall is too rigid then the blood pulse will not be sufficient to expand the aorta, too soft, then the wall expands excessively resulting in wall rupture (Karimi and Milewicz 2016; Cecelja and Chowienczyk 2012). Decreased aortic compliance is observed in multiple cardiovascular diseases, including hypertension, atherosclerosis and diabetes mellitus amongst other cardiovascular diseases (Cecelja and Chowienczyk 2012). Reduced compliance is associated with augmented arterial 
stiffness (Izzo and Shykoff 2001). In these conditions, the high pulse pressure is unable to expand the stiffened arterial wall, resulting in a faster pulse velocity that damages the microcirculation of vital organs (Cecelja and Chowienczyk 2012; Izzo and Shykoff 2001). Vascular smooth muscle cells are the predominant cell type in the aortic wall and disease associated changes in the mechanical landscape result in altered VSMC function (Halka et al. 2008; Shi and Chen 2015). These changes promote VSMC migration and are explored further below.

\section{VSMC function and phenotype}

Within physiological conditions, VSMCs exist in a quiescent contractile state and use actomyosin generated force to regulate vascular tone (Brozovich et al. 2016; Galmiche et al. 2013). Intermediate filaments, microtubules and actin comprise the key filamentous components of VSMCs (Ahmed and Warren 2018). The contractile machinery of VSMCs in particular are composed of thin actin filaments and thick myosin filaments, which collectively form the actomyosin complex (Ahmed and Warren 2018). As the blood pulse travels through the aorta, VSMCs become stretched, resulting in activation of stretch activated ion channels that facilitate $\mathrm{Ca}^{2+}$ entry and initiate VSMC contraction (Halka et al. 2008; Berridge 2008). In addition to this mechanically regulated VSMC contraction, soluble factors, including angiotensin II, bind to receptors and activate release of $\mathrm{Ca}^{2+}$ from intracellular stores to promote VSMC contraction (Berridge 2008; Inagami et al. 1997). A balance between the mechanical and soluble regulation of VSMC contraction determines aortic compliance and tone, resulting in controlled organ blood flow and pressure.

Despite existing in a contractile phenotype within a mature vessel, VSMCs retain a high plasticity and can dedifferentiate into a synthetic, migratory phenotype (Owens 2007; Alexander and Owens 2012). VSMC phenotypic switching is triggered in response to changes in the mechanical/biochemical signals, which are typically associated with development and cardiovascular diseases, such as atherosclerosis and hypertension (Alexander and Owens 2012). Signals that promote VSMC phenotypic switching include growth factors, mitogens, inflammatory mediators and mechanical stimuli (Alexander and Owens 2012; Owens 2007). When dedifferentiated, VSMCs migrate from the tunica media to the tunica intima, where the cells are unable to regulate vascular tone as effectively, but gain the ability to proliferate and increase ECM synthesis (Louis and Zahradka 2010; Yu et al. 2016). Phenotypic switching is associated with a variety of changes that increase VSMC migrational capacity and these are discussed further below.

\section{Rho GTPases}

The Rho-family of small GTPases are comprised of $\sim 20$ GTPases and they exist as a subfamily of the Ras superfamily (Hall 1998). They are well known to play a role in cell migration through various effectors proteins (Hall and Nobes 2000). The Rho GTPase proteins cycle between an active (GTP bound) form and an inactive (GDP bound) form. They are regulated temporally by the use of guanine nucleotide exchange factors (GEFs), GTPase-activating proteins (GAPs) and guanine nucleotide dissociation inhibitors (GDIs) (Huang et al. 2015; Bellanger et al. 2000; Ohta et al. 2006). GAPs inactivate GTPases by promoting hydrolysis of GTP into GDP, whereas GEFs prompt the exchange of GDP for GTP which triggers the enzymatic activity of the GTPase protein (Hall 1998). GDIs anchor the inactivated GTPase proteins within the cytoplasm, preventing interaction with the plasma membrane where it undergoes GDP/GTP exchange (Ridley 2001). Of these 20 GTPase proteins, RhoA, Rac1 and Cdc42 have been heavily characterised and are essential for the regulation of cell migration (Hall 1998; Hall and Nobes 2000).

The activation of RhoA is facilitated via the Go12/13 subunit, which binds to the p115 Rho GEF and stimulates exchange of GDP/GTP (Chen et al. 2012; Patel and Karginov 2014; Siehler 2009). Once active, RhoA can activate its downstream targets, including Rho-associated protein kinase 1/2 (ROCK1/2) (Wettschureck and Offermanns 2002). ROCK $1 / 2$ are major downstream RhoA effector proteins that belong to the AGC family of serine/threonine kinases (Wettschureck and Offermanns 2002). ROCK 1 and ROCK 2 possess a large number of similarities in both structure and function. Overall, they share a $65 \%$ identity in their amino acid sequence and can be seen to modulate mutual functions in endothelial, cardiac and smooth muscle cells (Hartmann et al. 2015). However, there is evidence that there may be isoform-specific roles of these kinases (Yoneda et al. 2005; Vega et al. 2011). One example was shown in fibroblast cells, where knockdown of ROCK 1 caused aberrant adhesion maturation and actin organisation (Yoneda et al. 2005). Contrastingly, ROCK2 specifically regulates the migratory capacity of prostate cancer cells (Vega et al. 2011). ROCK1 and ROCK2 also display differential regulation of cardiomyocyte function, ROCK1 regulates apoptosis whereas ROCK2 promotes hypertrophy (Hartmann et al. 2015). Utilisation of more selective inhibitors is therefore required to identify further isoform specific roles of the ROCK1/2 kinases (Liao et al. 2007). In VSMCs, ROCK $1 / 2$ activation affects cytoskeletal remodelling in two ways; it prevents actin depolymerisation, via inhibition of cofilin, and it can increase basal levels of phosphorylated myosin light chain, by inhibiting 
the activity of myosin light chain phosphatase (Amano et al. 2010; Liao et al. 2007; Ridley 2001). The regulation of cytoskeletal structure and actomyosin generated force production by RhoA plays an important role in VSMC migration (Ahmed and Warren 2018). Whether ROCK1 and ROCK 2 possess individual functions during VSMC migration remains to be fully explored.

Cdc42 and Rac1 also have multiple roles in cell migration. Cdc42 and Rac1 have been shown to regulate the formation of the filopodia and lamellipodia, respectively (Nobes and Hall 1995). Cdc42, via myotonic dystrophyrelated Cdc42-binding kinases (MRCK), shares a similar mechanism to ROCK and induces increased myosin light chain phosphorylation (Vicente-Manzanares et al. 2005). In contrast, Lamellipodia formation via Rac1 is facilitated through Arp2/3 complex activation and the uncapping of actin filaments present at the cell membrane (Ridley 2001). In addition, both $\mathrm{Cdc} 42$ and Rac1 interact with and activate p21 activated kinase (PAK). Once active, PAK can increase the stabilisation of the microtubules as well as regulate cell polarity of the cell via the activation of the PIX/PAK complex (Vicente-Manzanares et al. 2005).

The GTPases are critical regulators of the migratory process and more work is required to delineate cross talk between various GTPases and to further understand their dynamic regulation during cell migration.

\section{Actin polymerisation}

Actin polymerisation is critical for generating membrane protrusions at the leading edge during cell migration. Actin polymerisation requires nucleation via the formation of a stable actin trimer (Firat-Karalar and Welch 2011). This is the rate limiting step in the polymerisation process due to the instability of actin dimer intermediates (Firat-Karalar and Welch 2011). In order to facilitate actin polymerisation and overcome this kinetic demand, cells have evolved a wide range of actin-nucleating proteins (Firat-Karalar and Welch 2011). There are primarily two groups of actin polymerisation nucleators involved in cell migration, the formins, mDia1 and mDia2, and the Arp2/3 complex (Toure et al. 2012; Weise-Cross et al. 2015; Ning et al. 2011). mDia1 and mDia 2 bind to the barbed end of actin filaments and polymerise actin linearly, to form thin cellular protrusions called filopodia (Watanabe and Higashida 2004). mDia1/2 are multi-domain proteins that function as dimers, utilising their formin homology domain 2 (FH2) to bind to globular actin monomers in order to nucleate actin (Goh and Ahmed 2012; Watanabe and Higashida 2004). The protein profilin facilitates the polymerisation via interaction with the formin homology 1 (FH1) domain of mDia1/2 (Goh and Ahmed
2012). RhoA and $\mathrm{Cdc} 42$ regulate the $\mathrm{mDia} 1$ and $\mathrm{mDia} 2$, respectively (Watanabe and Higashida 2004).

The Arp $2 / 3$ complex is comprised of seven proteins, two of which are Arp2 and Arp3 (Weaver et al. 2003). It promotes actin polymerisation in a branched fashion, extending actin filaments at a $70^{\circ}$ angle from the sides of pre-existing filaments (Weaver et al. 2003). Independently, the Arp $2 / 3$ complex is intrinsically inactive, however it is activated by class I nucleation promoting factors (NPFs) (Firat-Karalar and Welch 2011). NPFs catalyse the reaction that forms lamellipodia by creating a new actin filament branch (Firat-Karalar and Welch 2011). Examples of such NPFs that regulate Arp $2 / 3$ complex activity are WAVE/Scar, Wiskott-Aldrich Syndrome protein (WASp) and N-WASp (Schenck et al. 2004; Zalevsky et al. 2001). The activity of these NPFs are primarily regulated by small GTPase proteins. WAVE/Scar is a multi-protein complex and the nucleation promoting activity is activated by Rac1, via the dissociation of the proteins Abi, Nap125 and Sra-1 from the complex (Schenck et al. 2004). In addition to this, Cdc42 has been shown to regulate both WASp and N-WASp (Vartiainen and Machesky 2004).

Cofilin is a key regulator of actin dynamics and is essential for directional cell migration. Cofilin is an actin filament severing protein and cells with low cofilin levels display defects in actin depolymerisation (Gerthoffer 2007). However, cofilin increases the dynamics of actin filament polymerisation at the leading edge by generating free barbed ends (Gungabissoon and Bamburg 2003; Ichetovkin et al. 2002). These free barbed ends promote actin filament branching via the Arp2/3 complex (Ichetovkin et al. 2002). The Arp2/3 nucleated actin branches are 10 times more stable on these recently severed free barbed ends than those produced on older filaments (Ichetovkin et al. 2002). Therefore, the functional activity of cofilin is essential in lamellipodia formation and must be tightly regulated. In resting cells, cofilin is directly bound to phosphatidylinositol 4,5-bisphosphate $\left(\mathrm{PIP}_{2}\right)$ at the plasma membrane. Upon stimulation, cofilin is dephosphorylated to sever actin filaments and promote actin polymerisation (Van Troys et al. 2008). The actin binding protein cortactin can associate with cofilin and inhibit cofilin's severing activity. Tyrosine phosphorylation of cortactin was found to promote cofilin dissociation from cortactin, activating the cofilin actin severing function (Van Troys et al. 2008; Gungabissoon and Bamburg 2003).

\section{Microtubules}

Microtubules are also key modulators of VSMC migration. Cell polarisation is a prerequisite for directed cell migration, and microtubules reorient themselves into an array that faces towards the leading edge of the cell (Watanabe et al. 
2005). This is achieved by selective stabilisation of microtubule plus ends and polarity is abolished by microtubule inhibitors (Watanabe et al. 2005). Dynamic instability of the microtubules is also a requirement for migration and fibroblast cell lines whose microtubules were experimentally stabilised showed a decrease in migrational capacity (Gundersen 2002). Small GTPase activity regulates microtubules dynamics. Cdc42 and Rac 1 activate PAK, which phosphorylates serine 16 and subsequently inactivates stathmin, a protein that is important in microtubule destabilisation (Cassimeris 2002; Daub et al. 2001; Wittmann et al. 2004). Therefore, Cdc42 and Rac1 signalling increase the stability of microtubules during cell migration.

\section{VSMC-ECM adhesions}

ECM adhesions are a critical component of the VSMC migratory process. During migration, VSMC-ECM adhesions assemble at the leading edge and disassemble at the trailing end (Vicente-Manzanares et al. 2005). For filopodial and lamellipodia protrusions to be maintained, they need to be physically anchored to the surrounding environment (Vicente-Manzanares et al. 2005; Ridley et al. 2003). Within VSMCs, integrins are the major receptor family that form VSMC-ECM attachments (Ross et al. 2013; Bottger et al. 1989). Integrins belong to the type I family of transmembrane glycoproteins and mediate VSMC-ECM interactions (Miyamoto et al. 1995). They are composed of three structural components; a large extracellular domain, a transmembrane domain and a short cytoplasmic domain (Miyamoto et al. 1995). Their heterodimeric ( $\beta$ and $\alpha$ subunit) isoforms allow them to have multiple compositions on the cell surface and to bind to various ECM proteins such as fibronectin and collagen-I (Seetharaman and Etienne-Manneville 2018). The beta integrin subunit links the ECM to the actin cytoskeleton (Legate and Fassler 2009; Seetharaman and Etienne-Manneville 2018). On the cytoplasmic face, adapter proteins, such as vinculin and talin, associate with the VSMC-ECM adhesion complex (Ross et al. 2013; Legate and Fassler 2009). These proteins serve to tether the integrin complex to the actin cytoskeleton. This allows for "outside in" signalling which activates signalling pathways within the cell (Wrighton 2013). Those mechanical signals cause the rearrangement of the actin cytoskeleton during migration (Ross et al. 2013). Studies conducted in rat VSMCs showed integrin to be activated by platelet derived growth factor (PDGF) which caused actin filaments to relocalise to the leading edge of the lamellipodia (Margolin et al. 2002).

Nascent VSMC-ECM adhesion formation at the leading edge of the cell requires integrin ligation, integrin clustering, phosphorylation of adhesion proteins and an intact actin filament meshwork (Miyamoto et al. 1995). Nascent
VSMC-ECM adhesions are structurally small and either quickly disassemble or mature into much larger adhesions via an actomyosin dependent process (Sun et al. 2014). VSMC-ECM adhesion organisation is controlled by a wide range of kinases, including focal adhesion kinase (FAK) and integrin linked kinase (ILK) (Abedi et al. 1995; Jiang et al. 1996). Focal adhesion kinase is a tyrosine kinase composed of an N-terminal 4.1 protein, ezrin, radixin and moesin (FERM) domain, a proline-rich region and C-terminal targeting domain (Mitra et al. 2005). It has been implicated in the regulation of cell motility (Mitra et al. 2005). Phosphorylation of FAK in VSMCs has been observed in both vascular injury or when stimulated with growth factors (Abedi et al. 1995; Jiang et al. 1996; Owens et al. 2001). Crystal structure analysis reveals that FAK is maintained in an inactive conformation via molecular interaction between the FERM domain and the catalytic domain (Lietha et al. 2007). FAK functions as a scaffold protein and directly phosphorylates talin and N-WASP (Wu et al. 2004; Feller et al. 2017). Integrin linked kinase (ILK) is a serine-threonine protein kinase, with a molecular mass of $\sim 50 \mathrm{kDa}$ (Dedhar et al. 1999). It is an important component of the focal adhesion complex and associates with vinculin and FAK (Nikolopoulos and Turner 2001; Stanchi et al. 2009). It has been shown to activate PI3 K and inhibit glycogen synthase kinase-3 $\beta$ in vascular development through the modulation of downstream targets (Li et al. 2016; Dedhar et al. 1999; Ho and Bendeck 2009). However, ILK predominantly serves as a scaffold protein rather than a kinase at VSMC-ECM adhesion sites during migration (Qin and Wu 2012; Vaynberg et al. 2018). ILK is composed of three subunits; the amino $\mathrm{N}$-terminal domain comprised of five ankyrin repeats, central PH-like domain and the C-terminal kinase catalytic domain (Dedhar et al. 1999). ILK co-localizes and interacts with several VSMC-ECM adhesion proteins, and such interactions coordinate actin polymerization and VSMC-ECM adhesion stability (Dedhar et al. 1999). It can also regulate the activation of Rac 1 and Cdc 42 by interacting with other scaffold proteins, such as $\alpha$-parvin and paxillin (Stanchi et al. 2009; Nikolopoulos and Turner 2001). ILK depleted cells showed decreased wound closure due to attenuated migrational capacity (Yuan et al. 2011; Li et al. 2016).

\section{VSMC-VSMC adhesions}

Intercellular adhesions also play an important role in migration of numerous cell types. These adhesions, much like VSMC-ECM adhesions, are structures which sense and respond to mechanical force (Borghi et al. 2012; Grashoff et al. 2010). Cadherins are the primary component of cell-cell adhesions and are comprised of three regions; an N-terminal domain, followed by a single transmembrane 
domain which leads to a small cytoplasmic tail (Sun et al. 2014a, b). Homodimeric interactions between the N-terminal regions of cadherin proteins from adjacent cells form the core of cell-cell contacts (Sun et al. 2014a, b). Lateral E-cadherin interactions between neighbouring cells facilitate collective migration in epithelial cells (Suffoletto et al. 2018). Within VSMCs, N-cadherin is the predominant isoform and has been shown to perform multiple roles. $\mathrm{N}$-cadherin is essential for efficient VSMC migration, yet it remains unknown whether N-cadherin can facilitate collective migration of VSMCs (Lyon et al. 2010).

\section{Rear-end detachment}

In addition to the leading edge, VSMC-ECM adhesions at the rear must detach in order to allow the cell body to propel forward (Ridley et al. 2003; Gerthoffer 2007). This is required to prevent cell damage occurring from the tension of the actomyosin generated force (Gerthoffer 2007; Vicente-Manzanares et al. 2005). Several mechanisms regulating VSMC-matrix adhesion detachment have been identified. These include contractility-promoted release, where the non-muscle myosin II contractile force exceeds the strength of the VSMC-ECM adhesion (Kirfel et al. 2004). $\mathrm{Ca}^{2+}$ levels also play an important role and activation of the phosphatase calcineurin, via a $\mathrm{Ca}^{2+}$-calmodulin dependent mechanism, also promotes adhesion detachment (Kirfel et al. 2004). Other mechanisms include modulating the affinity of the integrin for both the ECM ligands as well as the different cytosolic adaptors (Kirfel et al. 2004). Calpain and matrix metalloproteinase (MMP) activity also promote VSMC detachment (Gerthoffer 2007; Paulhe et al. 2001; Bendeck et al. 1994). Additionally, microtubules have shown to promote VSMC-ECM adhesion disassembly at the rear of the cell (Yang et al. 2010). Therefore, directed cell migration also depends on the dynamic regulation of microtubule function alongside actin polymerisation and adhesion turnover. Previous models have shown rear-end detachment plays a critical role in the reorientation and direction of the cell in migration (Theisen et al. 2012). Changes in migrational direction are higher following tail retraction, indicating that cell detachment precedes the directional change of the cell (Theisen et al. 2012). Conversely, increasing the stability of adhesions at the cell rear increased migrational directional persistence (Theisen et al. 2012).

Recently, a new mode of rapid cellular migration has been identified that involves rear end detachment to propel the cell over large distances (Wang et al. 2019). This mode is comprised of a two steps: (1) matrix stretch and (2) matrix recoil (Wang et al. 2019). Actomyosin activity first pulls ECM fibres to increase elastic strain energy (Wang et al. 2019). When this force exceeds the strength of the rear cell-ECM adhesions can withstand, it results in rapid matrix recoil and sudden cell movement via release of the strain energy (Wang et al. 2019). In addition, it was found that cell rear detachment can cause the formation of migration tracks as previous cell types, including fibroblasts and sarcoma cells, leave behind a trail of cell material which contains integrin micro aggregates (Kirfel et al. 2004; Rigort et al. 2004). This introduces a further method of rear cell detachment that could promote more efficient cell migration (Kirfel et al. 2004; Rigort et al. 2004). It is an intriguing possibility that retraction may facilitate rapid VSMC migration in 3D environments and deposit membrane fragments to promote directed migration. Whether VSMCs utilise rear end detachment to enhance their migrational capacity remains unknown and more research is required to examine the importance of retraction in VSMC migration.

\section{ECM composition}

The ECM is comprised of various structural glycoproteins such as collagen-I, elastin, fibronectin and vitronectin (Diez 2007). In the healthy aortic wall, collagen-I and elastin are the key structural ECM proteins that determine the aortic compliance (Shirwany and Zou 2010). The ECM is remodelled during vascular ageing and disease, resulting in collagen-I accumulation and elastin degradation (Shirwany and Zou 2010). Vascular ECM remodelling is further exaggerated when VSMCs dedifferentiate into their synthetic phenotype (Diez 2007). This phenotype is associated with increased synthesis of ECM components, including collagen-I, and enhanced matrix metalloproteinase (MMPs) enzymes (Okada et al. 1992; Bendeck et al. 1994). MMPs are classified into six major subclasses based on their dependency of $\mathrm{Zn}^{2+}$ binding for proteolytic activity (Fanjul-Fernandez et al. 2010). They are; collagenases, gelatinases, stromelysins, matrilysins, membrane-type (MT) and other non-classified MMPs (Fanjul-Fernandez et al. 2010; Myasoedova et al. 2018). Their activity is regulated by three mechanisms which are transcription, secretion and activation of the inactive zymogens and proenzymes (Myasoedova et al. 2018; Tallant et al. 2010; Galis and Khatri 2002). The activation of secreted pro-MMPs requires proteolytic removal of the pro-domain, by disrupting the Cys- $\mathrm{Zn}^{2+}$ interaction (Tallant et al. 2010). Membrane type MMPS such as MT1-MMP are known to activate pro-MMPs. (Myasoedova et al. 2018) Upon activation, MMPs degrade the elastic extracellular matrix and connective tissue (Myasoedova et al. 2018; Galis and Khatri 2002). In VSMCs, tightly controlled partial degradation of the ECM is a crucial step to allow cells to reposition during remodelling. However, uncontrolled MMP activation can result in damaged ECM 
that enables unregulated VSMC migration (Belo et al. 2015; Galis et al. 2002).

In atherosclerotic lesions, VSMCs display altered gene expression as a result of switching to their synthetic phenotype (Owens 2007). Analysis has shown that the fibrous plaques from these lesions contain a high concentration of collagen-I/III (Raines 2000). This uncontrolled increase in collagen expression by VSMCs during migration causes the thickening of the arterial wall which ultimately results in reduced aortic compliance (Cecelja and Chowienczyk 2012). Previous research shows that there is heterogeneity in the mechanical stiffness of both healthy and diseased tissue (Tracqui et al. 2011). This heterogeneity produces stiffness gradients that promotes directional movement in VSMCs. This type of migration is known as durotaxis (Hartman et al. 2016; Isenberg et al. 2009). Within atherosclerotic plaques, VSMCs are exposed to a wide range of ECM stiffnesses, with regions ranging between $5 \mathrm{kPa} \rightarrow 200 \mathrm{kPa}$ (Tracqui et al. 2011). The composition of the ECM is also important for VSMC durotaxis as fibronectin, an ECM component found in high abundance within atherosclerotic lesions, promotes VSMC directed cell migration (Hartman et al. 2016). Despite this, only a few studies have investigated how ECM composition and ECM stiffness gradients serve as VSMC directional cues.

\section{The nuclear lamina and VSMC migration}

The nuclear envelope (NE) and nuclear lamina have surprisingly emerged as regulators of cell migration. The NE is comprised of a double lipid bilayer that forms a physical barrier between the cytoplasm and nuclear interior (Lammerding 2011). The nuclear lamina underlies the NE and provides structural support to the NE (Gruenbaum et al. 2005). The nuclear lamina is a meshwork of filamentous A-type lamins (lamins A/C), B-type lamins (lamin B1 and B2) type lamins and associated lamin binding proteins (Gruenbaum et al. 2005). Importantly, the nuclear lamina indirectly associates with cytoplasmic filamentous intermediate filaments, microtubule and actin networks. This is achieved by a NE spanning complex known as the LInker of Nucleoskeleton and Cytoskeleton (LINC) complex (Crisp et al. 2006). The LINC complex consists of giant nesprin proteins that are tethered to the outer nuclear membrane by a Klarsicht, Anc1, Syne-1 Homology (KASH) domain (Zhang et al. 2001, 2007). The cytoplasmic facing nesprin proteins make multiple connections to the filamentous networks with multiple spectrin repeats and an N-terminal paired calponin homology domain, which directly binds filamentous actin (Zhang et al. 2001; Jayo et al. 2016; Kutscheidt et al. 2014). LINC complex stability is maintained via interactions between the nesprin KASH domain and the SUN-domain of the SUN family of proteins in the perinuclear space (Crisp et al. 2006;
Haque et al. 2006; Sosa et al. 2012). The SUN proteins span the inner nuclear membrane and interact with lamins $\mathrm{A} / \mathrm{C}$ in the nucleoplasm (Haque et al. 2010). Cytoskeletal derived biophysical signals are transmitted across the LINC complex and regulate association of the nuclear lamina with the NE and activated nuclear signalling (Arsenovic et al. 2016; Guilluy et al. 2014; Wu et al. 2014). The LINC complex also transmits inside out signals from the nuclear lamina to the cytoskeleton as disruption of the LINC complex or nuclear lamina triggers cytoskeletal reorganisation, altered GTPase signalling and impaired cell migration (Schwartz et al. 2017; Chambliss et al. 2013). However, the nature of these inside out signals remains unknown.

The A-type lamins are encoded by the LMNA gene (Rusinol and Sinensky 2006). Lamin C is directly generated from the LMNA gene (Rusinol and Sinensky 2006). In contrast, lamin A is generated from the prelamin A precursor protein that requires several post translational modification steps to generate mature lamin A (Rusinol and Sinensky 2006). Prel$\operatorname{amin} \mathrm{A}$ is farnesylated and is inserted into the INM (Rusinol and Sinensky 2006). To release mature lamin A from the INM, prelamin A must be processed by the metalloproteinase FACE1, which cleaves the C-terminal 15 amino acids of prelamin A, that include the farnesyl modification, to yield soluble mature lamin A (Rusinol and Sinensky 2006; Corrigan et al. 2005). Improper prelamin A processing is observed in Hutchinson-Gilford progeria syndrome (HGPS) accelerated ageing and in normal VSMC ageing. HGPS patients display accelerated ageing and possess a mutation that removes the FACE1 cleavage site in prelamin A (Rusinol and Sinensky 2006). This results in defective lamin A processing and prelamin A accumulation at the INM. VSMCs are severely affected in HGPS, suggesting that VSMCs are extremely sensitive to changes in lamin A processing (Ragnauth et al. 2010; Olive et al. 2010; McClintock et al. 2006). Prelamin A accumulation is also observed in normal VSMC ageing and is driven by loss of FACE1 expression (Ragnauth et al. 2010). In both situations, prelamin A accumulation is proposed to interfere with mature lamin A function. HGPSderived fibroblast cells exhibit cytoskeletal reorganisation, cell-ECM adhesion remodelling and reduced migrational capacity (Chang et al. 2019; Booth-Gauthier et al. 2013). Importantly, prelamin A accumulation or lamin A depletion in VSMCs showed similar changes in cytoskeletal and cell-ECM adhesion organisation as HGPS-derived fibroblasts (Porter et al. 2016). In VSMCs, the nuclear lamina influences migrational directional persistence via regulation of Rac1 (Porter et al. 2016). Although the mechanism of this regulation remains unknown, it is likely that the LINC complex is involved. Further experimentation is required to better understand the role of the nuclear lamina and LINC complex in VSMC migration within physiological and pathological environments. 


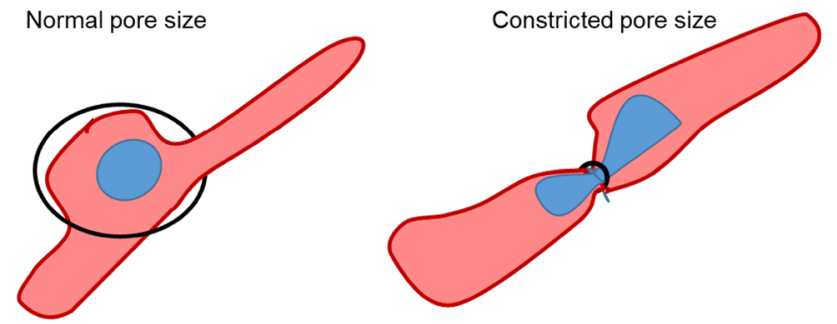

Fig. 2 Confined VSMC migration

\section{DNA damage and 3D migration}

Much of our knowledge discussed above has been generated on 2D surfaces. In vivo, cells must navigate complex $3 \mathrm{D}$ environments. The ECM is a porous network and as VSMCs move, they secrete MMPs to expand these pores, so VSMC migration is unhindered (Wolf et al. 2013). However, vascular calcification, where blood vessel walls calcify and become similar to bone, is observed in many vascular diseases, including atherosclerosis and diabetes (Liu and Shanahan 2011). In these conditions, VSMCs cannot degrade the calcified ECM to expand the pore size. How VSMCs migrate in these conditions remains completely unknown. Other cell types undergo a process known as constricted migration under conditions where they are unable to increase pore size (Wolf et al. 2013). The cytoplasm is not limited by ECM pore size, however, the nucleus is the largest and stiffest cellular organelle (Wolf et al. 2013) (Fig. 2). For cells to migrate though pores of limited size, cells use actomyosin generated force to squeeze the nucleus though (Davidson et al. 2014) (Fig. 2). This process results in nuclear deformation and places considerable pressure on the NE that ultimately results in NE damage and rupture (Denais et al. 2016; Xia et al. 2018). The nuclear envelope is a protective barrier separating the nuclear content from the cytoplasm. This allows compartmentalisation of crucial molecular components which facilitate processes such as DNA replication and RNA synthesis. NE rupture results in loss of this barrier function and induces DNA damage, which is predicted to promote genomic mutations that accelerate cancer metastasis (Xia et al. 2018; Irianto et al. 2017; Denais et al. 2016). DNA damage accumulation is known to accelerate prelamin A accumulation and VSMC ageing (Ragnauth et al. 2010). Aged VSMCs adopt a secretory phenotype that further accelerates blood vessel calcification (Liu et al. 2013). Therefore, VSMCs undergoing confined migration may promote the secretory phenotype and further accelerate vascular ageing (Liu et al. 2013; Ragnauth et al. 2010). Whether VSMCs undergo constricted migration within the calcified vessel wall remains unknown. However, given the importance of DNA damage in driving VSMC dysfunction and vessel wall deterioration, this remains a key unanswered question.

\section{Future directions}

Much research exists into the role of soluble factors and biochemical signalling in VSMC migration. However, we lack an understanding of two key areas: (1) how biophysical signalling and intercellular coupling between the cytoskeleton and nucleus contributes to VSMC migration; and (2) the role of insoluble factors, including matrix stiffness and porosity. Biophysical signalling and insoluble cues are known to change during ageing and vascular disease. Therefore, unravelling the mechanistic role of these changes will potentially identify novel therapeutic pathways to manipulate VSMC migration in ageing and vascular disease.

Funding This work was supported by two British Heart Foundation (BHF) Non-clinical PhD Studentships (FS/17/32/32916 and FS/18/35/33681).

\section{Compliance with ethical standards}

Conflict of interest The authors declare that they have no conflict of interest.

Open Access This article is distributed under the terms of the Creative Commons Attribution 4.0 International License (http://creativeco mmons.org/licenses/by/4.0/), which permits unrestricted use, distribution, and reproduction in any medium, provided you give appropriate credit to the original author(s) and the source, provide a link to the Creative Commons license, and indicate if changes were made.

\section{References}

Abedi H, Dawes KE, Zachary I (1995) Differential effects of plateletderived growth factor BB on p125 focal adhesion kinase and paxillin tyrosine phosphorylation and on cell migration in rabbit aortic vascular smooth muscle cells and Swiss 3 T3 fibroblasts. J Biol Chem 270:11367-11376

Ahmed S, Warren DT (2018) Vascular smooth muscle cell contractile function and mechanotransduction. Vessel Plus. https://doi. org/10.20517/2574-1209.2018.51b

Alexander MR, Owens GK (2012) Epigenetic control of smooth muscle cell differentiation and phenotypic switching in vascular development and disease. Annu Rev Physiol 74:13-40

Amano M, Nakayama M, Kaibuchi K (2010) Rho-kinase/ROCK: a key regulator of the cytoskeleton and cell polarity. Cytoskeleton 67:545-554

Arsenovic PT, Ramachandran I, Bathula K, Zhu R, Narang JD, Noll NA, Lemmon CA, Gundersen GG, Conway DE (2016) Nesprin$2 \mathrm{G}$, a component of the nuclear LINC complex, is subject to myosin-dependent tension. Biophys J 110:34-43

Bellanger JM, Astier C, Sardet C, Ohta Y, Stossel TP, Debant A (2000) The Rac1- and RhoG-specific GEF domain of Trio targets filamin to remodel cytoskeletal actin. Nat Cell Biol 2:888-892 
Belo VA, Guimaraes DA, Castro MM (2015) Matrix metalloproteinase 2 as a potential mediator of vascular smooth muscle cell migration and chronic vascular remodeling in hypertension. J Vasc Res 52:221-231

Bendeck MP, Zempo N, Clowes AW, Galardy RE, Reidy MA (1994) Smooth muscle cell migration and matrix metalloproteinase expression after arterial injury in the rat. Circ Res 75:539-545

Berridge MJ (2008) Smooth muscle cell calcium activation mechanisms. J Physiol 586:5047-5061

Booth-Gauthier EA, Du V, Ghibaudo M, Rape AD, Dahl KN, Ladoux B (2013) Hutchinson-Gilford progeria syndrome alters nuclear shape and reduces cell motility in three dimensional model substrates. Integr Biol 5:569-577

Borghi N, Sorokina M, Shcherbakova OG, Weis WI, Pruitt BL, Nelson WJ, Dunn AR (2012) E-cadherin is under constitutive actomyosin-generated tension that is increased at cell-cell contacts upon externally applied stretch. Proc Natl Acad Sci USA 109:12568-12573

Bottger BA, Hedin U, Johansson S, Thyberg J (1989) Integrin-type fibronectin receptors of rat arterial smooth muscle cells: isolation, partial characterization and role in cytoskeletal organization and control of differentiated properties. Differentiation $41: 158-167$

Brozovich FV, Nicholson CJ, Degen CV, Gao YZ, Aggarwal M, Morgan KG (2016) Mechanisms of vascular smooth muscle contraction and the basis for pharmacologic treatment of smooth muscle disorders. Pharmacol Rev 68:476-532

Cai Y, Nagel DJ, Zhou Q, Cygnar KD, Zhao H, Li F, Pi X, Knight PA, Yan C (2015) Role of cAMP-phosphodiesterase 1C signaling in regulating growth factor receptor stability, vascular smooth muscle cell growth, migration, and neointimal hyperplasia. Circ Res 116:1120-1132

Cassimeris L (2002) The oncoprotein 18/stathmin family of microtubule destabilizers. Curr Opin Cell Biol 14:18-24

Cecelja M, Chowienczyk P (2012) Role of arterial stiffness in cardiovascular disease. J R Soc Med Cardiovasc Dis 1:18

Chambliss AB, Khatau SB, Erdenberger N, Robinson DK, Hodzic D, Longmore GD, Wirtz D (2013) The LINC-anchored actin cap connects the extracellular milieu to the nucleus for ultrafast mechanotransduction. Sci Rep 3:1087

Chang W, Wang Y, Luxton GWG, Ostlund C, Worman HJ, Gundersen GG (2019) Imbalanced nucleocytoskeletal connections create common polarity defects in progeria and physiological aging. Proc Natl Acad Sci USA 116:3578-3583

Chen Z, Guo L, Hadas J, Gutowski S, Sprang SR, Sternweis PC (2012) Activation of p115-RhoGEF requires direct association of Galpha13 and the Dbl homology domain. J Biol Chem 287:25490-25500

Corrigan DP, Kuszczak D, Rusinol AE, Thewke DP, Hrycyna CA, Michaelis S, Sinensky MS (2005) Prelamin A endoproteolytic processing in vitro by recombinant Zmpste24. Biochem J 387:129-138

Crisp M, Liu Q, Roux K, Rattner JB, Shanahan C, Burke B, Stahl PD, Hodzic D (2006) Coupling of the nucleus and cytoplasm: role of the LINC complex. J Cell Biol 172:41-53

Daub H, Gevaert K, Vandekerckhove J, Sobel A, Hall A (2001) Rac/ $\mathrm{Cdc} 42$ and p65PAK regulate the microtubule-destabilizing protein stathmin through phosphorylation at serine 16. J Biol Chem 276:1677-1680

Davidson PM, Denais C, Bakshi MC, Lammerding J (2014) Nuclear deformability constitutes a rate-limiting step during cell migration in 3-D environments. Cell Mol Bioeng 7:293-306

Dedhar S, Williams B, Hannigan G (1999) Integrin-linked kinase (ILK): a regulator of integrin and growth-factor signalling. Trends Cell Biol 9:319-323
Denais CM, Gilbert RM, Isermann P, McGregor AL, te Lindert M, Weigelin B, Davidson PM, Friedl P, Wolf K, Lammerding J (2016) Nuclear envelope rupture and repair during cancer cell migration. Science 352:353-358

Diez J (2007) Arterial stiffness and extracellular matrix. Adv Cardiol 44:76-95

Fanjul-Fernandez M, Folgueras AR, Cabrera S, Lopez-Otin C (2010) Matrix metalloproteinases: evolution, gene regulation and functional analysis in mouse models. Biochim Biophys Acta 1803:3-19

Feller L, Khammissa RAG, Lemmer J (2017) Biomechanical cell regulatory networks as complex adaptive systems in relation to cancer. Cancer Cell Int 17:16

Firat-Karalar EN, Welch MD (2011) New mechanisms and functions of actin nucleation. Curr Opin Cell Biol 23:4-13

Galis ZS, Khatri JJ (2002) Matrix metalloproteinases in vascular remodeling and atherogenesis: the good, the bad, and the ugly. Circ Res 90:251-262

Galis ZS, Johnson C, Godin D, Magid R, Shipley JM, Senior RM, Ivan E (2002) Targeted disruption of the matrix metalloproteinase-9 gene impairs smooth muscle cell migration and geometrical arterial remodeling. Circ Res 91:852-859

Galmiche G, Labat C, Mericskay M, Aissa KA, Blanc J, Retailleau K, Bourhim M, Coletti D, Loufrani L, Gao-Li J, Feil R, Challande P, Henrion D, Decaux JF, Regnault V, Lacolley P, Li Z (2013) Inactivation of serum response factor contributes to decrease vascular muscular tone and arterial stiffness in mice. Circ Res 112:1035-1045

Gerthoffer WT (2007) Mechanisms of vascular smooth muscle cell migration. Circ Res 100:607-621

Goh WI, Ahmed S (2012) mDia1-3 in mammalian filopodia. Commun Integr Biol 5:340-344

Grashoff C, Hoffman BD, Brenner MD, Zhou R, Parsons M, Yang MT, McLean MA, Sligar SG, Chen CS, Ha T, Schwartz MA (2010) Measuring mechanical tension across vinculin reveals regulation of focal adhesion dynamics. Nature 466:263-266

Gruenbaum Y, Margalit A, Goldman RD, Shumaker DK, Wilson KL (2005) The nuclear lamina comes of age. Nat Rev Mol Cell Biol 6:21-31

Guilluy C, Osborne LD, Van Landeghem L, Sharek L, Superfine R, Garcia-Mata R, Burridge K (2014) Isolated nuclei adapt to force and reveal a mechanotransduction pathway in the nucleus. Nat Cell Biol 16:376-381

Gundersen GG (2002) Evolutionary conservation of microtubulecapture mechanisms. Nat Rev Mol Cell Biol 3:296-304

Gungabissoon RA, Bamburg JR (2003) Regulation of growth cone actin dynamics by ADF/cofilin. J Histochem Cytochem 51:411-420

Halka AT, Turner NJ, Carter A, Ghosh J, Murphy MO, Kirton JP, Kielty CM, Walker MG (2008) The effects of stretch on vascular smooth muscle cell phenotype in vitro. Cardiovasc Pathol 17:98-102

Hall A (1998) Rho GTPases and the actin cytoskeleton. Science 279:509-514

Hall A, Nobes CD (2000) Rho GTPases: molecular switches that control the organization and dynamics of the actin cytoskeleton. Philos Trans R Soc Lond B 355:965-970

Haque F, Lloyd DJ, Smallwood DT, Dent CL, Shanahan CM, Fry AM, Trembath RC, Shackleton S (2006) SUN1 interacts with nuclear lamin A and cytoplasmic nesprins to provide a physical connection between the nuclear lamina and the cytoskeleton. Mol Cell Biol 26:3738-3751

Haque F, Mazzeo D, Patel JT, Smallwood DT, Ellis JA, Shanahan CM, Shackleton S (2010) Mammalian SUN protein interaction networks at the inner nuclear membrane and their role in laminopathy disease processes. J Biol Chem 285:3487-3498 
Hartman CD, Isenberg BC, Chua SG, Wong JY (2016) Vascular smooth muscle cell durotaxis depends on extracellular matrix composition. Proc Natl Acad Sci USA 113:11190-11195

Hartmann S, Ridley AJ, Lutz S (2015) The function of rho-associated kinases ROCK1 and ROCK2 in the pathogenesis of cardiovascular disease. Front Pharmacol 6:276

Ho B, Bendeck MP (2009) Integrin linked kinase (ILK) expression and function in vascular smooth muscle cells. Cell Adh Migr 3:174-176

Huang HY, Zhang WT, Jiang WY, Chen SZ, Liu Y, Ge X, Li X, Dang YJ, Wen B, Liu XH, Lu HJ, Tang QQ (2015) RhoGDIbeta inhibits bone morphogenetic protein 4 (BMP4)-induced Adipocyte lineage commitment and favors smooth muscle-like cell differentiation. J Biol Chem 290:11119-11129

Ichetovkin I, Grant W, Condeelis J (2002) Cofilin produces newly polymerized actin filaments that are preferred for dendritic nucleation by the Arp2/3 complex. Curr Biol 12:79-84

Inagami T, Eguchi S, Tsuzuki S, Ichiki T (1997) Angiotensin II receptors AT1 and AT2-new mechanisms of signaling and antagonistic effects of AT1 and AT2. Jpn Circ J 61:807-813

Irianto J, Xia Y, Pfeifer CR, Athirasala A, Ji J, Alvey C, Tewari M, Bennett RR, Harding SM, Liu AJ, Greenberg RA, Discher DE (2017) DNA damage follows repair factor depletion and portends genome variation in cancer cells after pore migration. Curr Biol 27:210-223

Isenberg BC, Dimilla PA, Walker M, Kim S, Wong JY (2009) Vascular smooth muscle cell durotaxis depends on substrate stiffness gradient strength. Biophys J 97:1313-1322

Izzo JL Jr, Shykoff BE (2001) Arterial stiffness: clinical relevance, measurement, and treatment. Rev Cardiovasc Med 2(29-34):37-40

Jayo A, Malboubi M, Antoku S, Chang W, Ortiz-Zapater E, Groen C, Pfisterer K, Tootle T, Charras G, Gundersen GG, Parsons M (2016) Fascin regulates nuclear movement and deformation in migrating cells. Dev Cell 38:371-383

Jiang B, Yamamura S, Nelson PR, Mureebe L, Kent KC (1996) Differential effects of platelet-derived growth factor isotypes on human smooth muscle cell proliferation and migration are mediated by distinct signaling pathways. Surgery 120:427431; (discussion 32)

Karimi A, Milewicz DM (2016) Structure of the Elastin-contractile units in the thoracic aorta and how genes that cause thoracic aortic aneurysms and dissections disrupt this structure. Can $\mathbf{J}$ Cardiol 32:26-34

Kerr JS, Jacques RO, Moyano Cardaba C, Tse T, Sexton D, Mueller A (2013) Differential regulation of chemotaxis: role of Gbetagamma in chemokine receptor-induced cell migration. Cell Signal 25:729-735

Kirfel G, Rigort A, Borm B, Herzog V (2004) Cell migration: mechanisms of rear detachment and the formation of migration tracks. Eur J Cell Biol 83:717-724

Kutscheidt S, Zhu R, Antoku S, Luxton GW, Stagljar I, Fackler OT, Gundersen GG (2014) FHOD1 interaction with nesprin-2G mediates TAN line formation and nuclear movement. Nat Cell Biol 16:708-715

Lammerding J (2011) Mechanics of the nucleus. Compr Physiol 1:783-807

Legate KR, Fassler R (2009) Mechanisms that regulate adaptor binding to beta-integrin cytoplasmic tails. J Cell Sci 122:187-198

Li G, Li YY, Sun JE, Lin WH, Zhou RX (2016) ILK-PI3 K/AKT pathway participates in cutaneous wound contraction by regulating fibroblast migration and differentiation to myofibroblast. Lab Invest 96:741-751

Liao JK, Seto M, Noma K (2007) Rho kinase (ROCK) inhibitors. J Cardiovasc Pharmacol 50:17-24
Lietha D, Cai X, Ceccarelli DF, Li Y, Schaller MD, Eck MJ (2007) Structural basis for the autoinhibition of focal adhesion kinase. Cell 129:1177-1187

Liu Y, Shanahan CM (2011) Signalling pathways and vascular calcification. Front Biosci 16:1302-1314

Liu Y, Drozdov I, Shroff R, Beltran LE, Shanahan CM (2013) Prelamin A accelerates vascular calcification via activation of the DNA damage response and senescence-associated secretory phenotype in vascular smooth muscle cells. Circ Res 112:e99-e109

Louis SF, Zahradka P (2010) Vascular smooth muscle cell motility: from migration to invasion. Exp Clin Cardiol 15:e75-e85

Lyon CA, Koutsouki E, Aguilera CM, Blaschuk OW, George SJ (2010) Inhibition of $\mathrm{N}$-cadherin retards smooth muscle cell migration and intimal thickening via induction of apoptosis. J Vasc Surg 52:1301-1309

Margolin L, Fishbein I, Banai S, Golomb G, Reich R, Perez LS, Gertz SD (2002) Metalloproteinase inhibitor attenuates neointima formation and constrictive remodeling after angioplasty in rats: augmentative effect of alpha(v)beta(3) receptor blockade. Atherosclerosis 163:269-277

McClintock D, Gordon LB, Djabali K (2006) Hutchinson-Gilford progeria mutant lamin A primarily targets human vascular cells as detected by an anti-Lamin A G608G antibody. Proc Natl Acad Sci USA 103:2154-2159

Mitra SK, Hanson DA, Schlaepfer DD (2005) Focal adhesion kinase: in command and control of cell motility. Nat Rev Mol Cell Biol 6:56-68

Miyamoto S, Teramoto H, Coso OA, Gutkind JS, Burbelo PD, Akiyama SK, Yamada KM (1995) Integrin function: molecular hierarchies of cytoskeletal and signaling molecules. J Cell Biol 131:791-805

Myasoedova VA, Chistiakov DA, Grechko AV, Orekhov AN (2018) Matrix metalloproteinases in pro-atherosclerotic arterial remodeling. J Mol Cell Cardiol 123:159-167

Nikolopoulos SN, Turner CE (2001) Integrin-linked kinase (ILK) binding to paxillin LD1 motif regulates ILK localization to focal adhesions. J Biol Chem 276:23499-23505

Ning Y, Sun Q, Dong Y, Xu W, Zhang W, Huang H, Li Q (2011) Slit2$\mathrm{N}$ inhibits PDGF-induced migration in rat airway smooth muscle cells: WASP and Arp2/3 involved. Toxicology 283:32-40

Nobes CD, Hall A (1995) Rho, rac, and cdc42 GTPases regulate the assembly of multimolecular focal complexes associated with actin stress fibers, lamellipodia, and filopodia. Cell 81:53-62

Ohta Y, Hartwig JH, Stossel TP (2006) FilGAP, a Rho- and ROCKregulated GAP for Rac binds filamin A to control actin remodelling. Nat Cell Biol 8:803-814

Okada Y, Katsuda S, Matsui Y, Nakanishi I (1992) The modulation of collagen synthesis in cultured arterial smooth muscle cells by platelet-derived growth factor. Cell Biol Int Rep 16:1015-1022

Olive M, Harten I, Mitchell R, Beers JK, Djabali K, Cao K, Erdos MR, Blair C, Funke B, Smoot L, Gerhard-Herman M, Machan JT, Kutys R, Virmani R, Collins FS, Wight TN, Nabel EG, Gordon LB (2010) Cardiovascular pathology in Hutchinson-Gilford progeria: correlation with the vascular pathology of aging. Arterioscler Thromb Vasc Biol 30:2301-2309

Owens GK (2007) Molecular control of vascular smooth muscle cell differentiation and phenotypic plasticity. Novartis Found Symp 283:174-191; discussion 91-93, 238-241.

Owens LV, Xu L, Marston WA, Yang X, Farber MA, Iacocca MV, Cance WG, Keagy BA (2001) Overexpression of the focal adhesion kinase (p125FAK) in the vascular smooth muscle cells of intimal hyperplasia. J Vasc Surg 34:344-349

Patel M, Karginov AV (2014) Phosphorylation-mediated regulation of GEFs for RhoA. Cell Adh Migr 8:11-18

Paulhe F, Bogyo A, Chap H, Perret B, Racaud-Sultan C (2001) Vascular smooth muscle cell spreading onto fibrinogen is regulated by 
calpains and phospholipase C. Biochem Biophys Res Commun 288:875-881

Porter LJ, Holt MR, Soong D, Shanahan CM, Warren DT (2016) Prelamin A accumulation attenuates rac1 activity and increases the intrinsic migrational persistence of aged vascular smooth muscle cells. Cells 5:41

Qin J, Wu C (2012) ILK: a pseudokinase in the center stage of cellmatrix adhesion and signaling. Curr Opin Cell Biol 24:607-613

Ragnauth CD, Warren DT, Liu Y, McNair R, Tajsic T, Figg N, Shroff R, Skepper J, Shanahan CM (2010) Prelamin A acts to accelerate smooth muscle cell senescence and is a novel biomarker of human vascular aging. Circulation 121:2200-2210

Raij L, Gonzalez-Ochoa AM (2011) Vascular compliance in blood pressure. Curr Opin Nephrol Hypertens 20:457-464

Raines EW (2000) The extracellular matrix can regulate vascular cell migration, proliferation, and survival: relationships to vascular disease. Int J Exp Pathol 81:173-182

Ridley AJ (2001) Rho GTPases and cell migration. J Cell Sci 114:2713-2722

Ridley AJ, Schwartz MA, Burridge K, Firtel RA, Ginsberg MH, Borisy G, Parsons JT, Horwitz AR (2003) Cell migration: integrating signals from front to back. Science 302:1704-1709

Rigort A, Grunewald J, Herzog V, Kirfel G (2004) Release of integrin macroaggregates as a mechanism of rear detachment during keratinocyte migration. Eur J Cell Biol 83:725-733

Ross TD, Coon BG, Yun S, Baeyens N, Tanaka K, Ouyang M, Schwartz MA (2013) Integrins in mechanotransduction. Curr Opin Cell Biol 25:613-618

Rusinol AE, Sinensky MS (2006) Farnesylated lamins, progeroid syndromes and farnesyl transferase inhibitors. J Cell Sci 119:3265-3272

Schenck A, Qurashi A, Carrera P, Bardoni B, Diebold C, Schejter E, Mandel JL, Giangrande A (2004) WAVE/SCAR, a multifunctional complex coordinating different aspects of neuronal connectivity. Dev Biol 274:260-270

Scherberich A, Campos-Toimil M, Ronde P, Takeda K, Beretz A (2000) Migration of human vascular smooth muscle cells involves serum-dependent repeated cytosolic calcium transients. J Cell Sci 113(Pt 4):653-662

Schwartz C, Fischer M, Mamchaoui K, Bigot A, Lok T, Verdier C, Duperray A, Michel R, Holt I, Voit T, Quijano-Roy S, Bonne G, Coirault C (2017) Lamins and nesprin-1 mediate inside-out mechanical coupling in muscle cell precursors through FHOD1. Sci Rep 7:1253

Seetharaman S, Etienne-Manneville S (2018) Integrin diversity brings specificity in mechanotransduction. Biol Cell 110:49-64

Shi N, Chen SY (2015) Smooth muscle cell differentiation: model systems, regulatory mechanisms, and vascular diseases. J Cell Physiol 231:777-787

Shirwany NA, Zou MH (2010) Arterial stiffness: a brief review. Acta Pharmacol Sin 31:1267-1276

Siehler S (2009) Regulation of RhoGEF proteins by G12/13-coupled receptors. Br J Pharmacol 158:41-49

Sosa BA, Rothballer A, Kutay U, Schwartz TU (2012) LINC complexes form by binding of three KASH peptides to domain interfaces of trimeric SUN proteins. Cell 149:1035-1047

Stanchi F, Grashoff C, Nguemeni Yonga CF, Grall D, Fassler R, Van Obberghen-Schilling E (2009) Molecular dissection of the ILKPINCH-parvin triad reveals a fundamental role for the ILK kinase domain in the late stages of focal-adhesion maturation. J Cell Sci 122:1800-1811

Suffoletto K, Jetta D, Hua SZ (2018) E-cadherin mediated lateral interactions between neighbor cells necessary for collective migration. J Biomech 71:159-166

Sun Z, Lambacher A, Fassler R (2014a) Nascent adhesions: from fluctuations to a hierarchical organization. Curr Biol 24:R801-R803
Sun Z, Parrish AR, Hill MA, Meininger GA (2014b) N-cadherin, a vascular smooth muscle cell-cell adhesion molecule: function and signaling for vasomotor control. Microcirculation 21:208-218

Tahir H, Niculescu I, Bona-Casas C, Merks RM, Hoekstra AG (2015) An in silico study on the role of smooth muscle cell migration in neointimal formation after coronary stenting. J R Soc Interface 12:20150358

Tallant C, Marrero A, Gomis-Ruth FX (2010) Matrix metalloproteinases: fold and function of their catalytic domains. Biochim Biophys Acta 1803:20-28

Theisen U, Straube E, Straube A (2012) Directional persistence of migrating cells requires Kif1C-mediated stabilization of trailing adhesions. Dev Cell 23:1153-1166

Toure F, Fritz G, Li Q, Rai V, Daffu G, Zou YS, Rosario R, Ramasamy R, Alberts AS, Yan SF, Schmidt AM (2012) Formin mDia1 mediates vascular remodeling via integration of oxidative and signal transduction pathways. Circ Res 110:1279-1293

Tracqui P, Broisat A, Toczek J, Mesnier N, Ohayon J, Riou L (2011) Mapping elasticity moduli of atherosclerotic plaque in situ via atomic force microscopy. J Struct Biol 174:115-123

Van Troys M, Huyck L, Leyman S, Dhaese S, Vandekerkhove J, Ampe C (2008) Ins and outs of ADF/cofilin activity and regulation. Eur J Cell Biol 87:649-667

Vartiainen MK, Machesky LM (2004) The WASP-Arp2/3 pathway: genetic insights. Curr Opin Cell Biol 16:174-181

Vaynberg J, Fukuda K, Lu F, Bialkowska K, Chen Y, Plow EF, Qin J (2018) Non-catalytic signaling by pseudokinase ILK for regulating cell adhesion. Nat Commun 9:4465

Vega FM, Fruhwirth G, Ng T, Ridley AJ (2011) RhoA and RhoC have distinct roles in migration and invasion by acting through different targets. J Cell Biol 193:655-665

Vicente-Manzanares M, Webb DJ, Horwitz AR (2005) Cell migration at a glance. J Cell Sci 118:4917-4919

Wagenseil JE, Mecham RP (2009) Vascular extracellular matrix and arterial mechanics. Physiol Rev 89:957-989

Wang WY, Davidson CD, Lin D, Baker BM (2019) Actomyosin contractility-dependent matrix stretch and recoil induces rapid cell migration. Nat Commun 10:1186

Watanabe N, Higashida C (2004) Formins: processive cappers of growing actin filaments. Exp Cell Res 301:16-22

Watanabe T, Noritake J, Kaibuchi K (2005) Regulation of microtubules in cell migration. Trends Cell Biol 15:76-83

Weaver AM, Young ME, Lee WL, Cooper JA (2003) Integration of signals to the Arp2/3 complex. Curr Opin Cell Biol 15:23-30

Weise-Cross L, Taylor JM, Mack CP (2015) Inhibition of diaphanous formin signaling in vivo impairs cardiovascular development and alters smooth muscle cell phenotype. Arterioscler Thromb Vasc Biol 35:2374-2383

Wettschureck N, Offermanns S (2002) Rho/Rho-kinase mediated signaling in physiology and pathophysiology. J Mol Med 80:629-638

Wittmann T, Bokoch GM, Waterman-Storer CM (2004) Regulation of microtubule destabilizing activity of Op18/stathmin downstream of Rac1. J Biol Chem 279:6196-6203

Wolf K, Te Lindert M, Krause M, Alexander S, Te Riet J, Willis AL, Hoffman RM, Figdor CG, Weiss SJ, Friedl P (2013) Physical limits of cell migration: control by ECM space and nuclear deformation and tuning by proteolysis and traction force. J Cell Biol 201:1069-1084

Wrighton KH (2013) Cell adhesion: the 'ins' and 'outs' of integrin signalling. Nat Rev Mol Cell Biol 14:752

Wu X, Suetsugu S, Cooper LA, Takenawa T, Guan JL (2004) Focal adhesion kinase regulation of N-WASP subcellular localization and function. J Biol Chem 279:9565-9576 
Wu J, Kent IA, Shekhar N, Chancellor TJ, Mendonca A, Dickinson RB, Lele TP (2014) Actomyosin pulls to advance the nucleus in a migrating tissue cell. Biophys J 106:7-15

Xia Y, Ivanovska IL, Zhu K, Smith L, Irianto J, Pfeifer CR, Alvey CM, Ji J, Liu D, Cho S, Bennett RR, Liu AJ, Greenberg RA, Discher DE (2018) Nuclear rupture at sites of high curvature compromises retention of DNA repair factors. J Cell Biol 217:3796-3808

Yang H, Ganguly A, Cabral F (2010) Inhibition of cell migration and cell division correlates with distinct effects of microtubule inhibiting drugs. J Biol Chem 285:32242-32250

Yoneda A, Multhaupt HA, Couchman JR (2005) The Rho kinases I and II regulate different aspects of myosin II activity. J Cell Biol 170:443-453

Yu B, Wong MM, Potter CM, Simpson RM, Karamariti E, Zhang Z, Zeng L, Warren D, Hu Y, Wang W, Xu Q (2016) Vascular stem/progenitor cell migration induced by smooth muscle cellderived chemokine (C-C motif) ligand 2 and chemokine (C-X-C motif) ligand 1 contributes to neointima formation. Stem Cells 34:2368-2380

Yuan L, Sanders MA, Basson MD (2011) ILK mediates the effects of strain on intestinal epithelial wound closure. Am J Physiol Cell Physiol 300:C356-C367
Zalevsky J, Lempert L, Kranitz H, Mullins RD (2001) Different WASP family proteins stimulate different Arp2/3 complex-dependent actin-nucleating activities. Curr Biol 11:1903-1913

Zhang Q, Skepper JN, Yang F, Davies JD, Hegyi L, Roberts RG, Weissberg PL, Ellis JA, Shanahan CM (2001) Nesprins: a novel family of spectrin-repeat-containing proteins that localize to the nuclear membrane in multiple tissues. J Cell Sci 114:4485-4498

Zhang Q, Bethmann C, Worth NF, Davies JD, Wasner C, Feuer A, Ragnauth CD, Yi Q, Mellad JA, Warren DT, Wheeler MA, Ellis JA, Skepper JN, Vorgerd M, Schlotter-Weigel B, Weissberg PL, Roberts RG, Wehnert M, Shanahan CM (2007) Nesprin-1 and -2 are involved in the pathogenesis of Emery Dreifuss muscular dystrophy and are critical for nuclear envelope integrity. Hum Mol Genet 16:2816-2833

Publisher's Note Springer Nature remains neutral with regard to jurisdictional claims in published maps and institutional affiliations. 